\title{
Conquering the Sahara and Arabian deserts: systematics and biogeography of Stenodactylus geckos (Reptilia: Gekkonidae)
}

\author{
Margarita Metallinou', Edwin Nicholas Arnold ${ }^{2}$, Pierre-André Crochet ${ }^{3}$, Philippe Geniez ${ }^{4}$, José Carlos Brito 5 ,
} Petros Lymberakis ${ }^{6}$, Sherif Baha El Din ${ }^{7}$, Roberto Sindaco ${ }^{8}$, Michael Robinson ${ }^{9}$ and Salvador Carranza ${ }^{1 *}$

\begin{abstract}
Background: The evolutionary history of the biota of North Africa and Arabia is inextricably tied to the complex geological and climatic evolution that gave rise to the prevalent deserts of these areas. Reptiles constitute an exemplary group in the study of the arid environments with numerous well-adapted members, while recent studies using reptiles as models have unveiled interesting biogeographical and diversification patterns. In this study, we include 207 specimens belonging to all 12 recognized species of the genus Stenodactylus. Molecular phylogenies inferred using two mitochondrial (12S rRNA and 16S rRNA) and two nuclear (c-mos and RAG-2) markers are employed to obtain a robust time-calibrated phylogeny, as the base to investigate the inter- and intraspecific relationships and to elucidate the biogeographical history of Stenodacty/us, a genus with a large distribution range including the arid and hyper-arid areas of North Africa and Arabia.
\end{abstract}

Results: The phylogenetic analyses of molecular data reveal the existence of three major clades within the genus Stenodactylus, which is supported by previous studies based on morphology. Estimated divergence times between clades and sub-clades are shown to correlate with major geological events of the region, the most important of which is the opening of the Red Sea, while climatic instability in the Miocene is hypothesized to have triggered diversification. High genetic variability is observed in some species, suggesting the existence of some undescribed species. The S. petrii - S. stenurus species complex is in need of a thorough taxonomic revision. New data is presented on the distribution of the sister species S. sthenodactylus and S. mauritanicus.

Conclusions: The phylogenetic hypothesis for the genus Stenodactylus presented in this work permits the reconstruction of the biogeographical history of these common desert dwellers and confirms the importance of the opening of the Red Sea and the climatic oscillations of the Miocene as major factors in the diversification of the biota of North Africa and Arabia. Moreover, this study traces the evolution of this widely distributed and highly specialized group, investigates the patterns of its high intraspecific diversity and elucidates its systematics.

Keywords: Stenodactylus, Gekkonidae, Arabia, North Africa, Phylogeny, Biogeography, Desert, Red Sea

\section{Background}

North Africa and Arabia are home to a unique fauna and flora that has been shaped by the combination of several factors including the harsh climatic conditions of the Sahara and Arabian deserts, the episodic appearance of humid cycles, and by the complex geological

\footnotetext{
* Correspondence: salvador.carranza@ibe.upf-csic.es

'Institute of Evolutionary Biology (CSIC-UPF), Passeig Marítim de la Barceloneta 37-49, Barcelona 08003, Spain

Full list of author information is available at the end of the article
}

evolution of the area [1-9]. One of the most important geological phenomena of the entire Cenozoic that occurred in this area was the break-up of the Arabian plate from Africa. Tectonic activity started approximately $30 \mathrm{Ma}$ ago at the central Gulf of Aden with the formation of a rift basin in the Eritrean Red Sea and initial rifting at the Afar zone. A second phase of volcanism occurred $24 \mathrm{Ma}$ ago, causing extension and rifting throughout the entire Red Sea, from Yemen to Egypt, as well as uplifting of the newly-formed continental

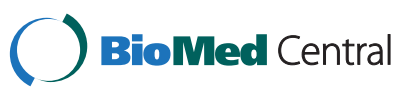


shoulders [1]. Nevertheless, fluctuations of the sea level during the Miocene permitted the formation of transient land connections $[1,10]$ that were subsequently lost [11].

The establishment of the Afro-Arabia - Eurasia land bridge (Gomphotherium bridge) was another crucial event with major biogeographical implications [12-14]. Following the opening of the Gulf of Aden and the Red Sea and with the counterclockwise rotation of the Arabian plate, a first connection was presumably formed between the latter and the Anatolian plate, and subsequently with Eurasia. Although the connection between the Mediterranean Sea and the Indian Ocean is hypothesized to have been re-established in the Upper Middle Miocene, around $15 \mathrm{Ma}$ ago, it is believed that posterior to this date the land bridge has been continuously present [15]. Important faunal and floral exchanges have been attributed to the establishment of this connection ([12-14] and references therein).

Although the origin of the Sahara and Arabian deserts is still hotly debated [16-19], it is generally accepted that climatic development in the late Miocene, as a result of major growth of the East Antarctic Ice Sheet and polar cooling, lead to an increase in aridification of midlatitude continental regions [4] and that this had a profound effect on the diversification of faunas [20-22].

Reptiles are among the commonest inhabitants of arid areas and have long been used in biogeographic, ecological and evolutionary studies [23], constituting thus excellent models to investigate how diversity is originated and maintained. Several cases of faunal exchanges in both directions between North Africa and Arabia have been described (e.g. $[2,13,24])$ showing that there is not a single pattern, but rather different hypotheses including both vicariance and dispersal, heavily dependent on the estimated timeframe of the events. Moreover, several studies have shown that climatic changes towards aridity and contraction/ expansion of the Sahara and Arabian deserts have played a decisive role in reptile species diversification [25-29].

Gekkonid lizards of the genus Stenodactylus Fitzinger, 1826 [30] are one of the most characteristic and abundant elements of the fauna of the arid and hyper-arid regions of Arabia and North Africa [31]. The genus comprises twelve species that are distributed in a more or less continuous range across northern Africa and Arabia, with an apparently isolated population in northern Kenya and extending around the Arabian Gulf to coastal southwestern Iran ([32,33]; see Figure 1). Up to three species may occur at a single locality and, where such sympatry exists, resource partitioning is largely achieved by microhabitat segregation, with species occupying different soil types [34]. Gravel plains, hard sand and aeolian soft sand all have their characteristic species that show specialized morphological adaptations. These include the presence of depressed and fringed toes, which increase the surface area and improve grip in the aeolian sand dune specialists Stenodactylus doriae (Blanford, 1874 [35]), S. petrii Anderson, 1896 [36] and S. arabicus (Haas, 1957 [37]). Extensive webbing is also observed between the fingers for efficient sand burrowing in S. arabicus $[31,32,38]$. When two species are regularly found on the same substrate, they greatly differ in size and there are corresponding differences in the size of prey taken [32].

Morphologically, Stenodactylus is fairly homogeneous and all species exhibit phalangeal reduction that produces a formula of 2.3.3.4.3 on both fore and hind limbs and are also characterized by a very high scleral ossicle number (20-28) [31,39]. A morphology-based phylogenetic hypothesis has been proposed by Arnold (1980) [31]. Although these two characters are also present in Pseudoceramodactylus khobarensis Haas, 1957 [37], which was widely accepted as a Stenodactylus member [31,39], a recent phylogenetic study by Fujita and Papenfuss (2011) [40] including specimens of the former and six out of the twelve species of the genus Stenodactylus proposed the resurrection of the genus Pseudoceramodactylus. This was done in order to deal with the resulting paraphyly of Stenodactylus, caused by the branching of two representatives of the genus Tropiocolotes between P. khobarensis and the six Stenodactylus included in their analyses. Their molecular analyses also uncovered high levels of genetic divergence between the different Stenodactylus species. Genetic variability within some of the species, like $S$. arabicus and $S$. doriae, was also high and this could be linked to biogeographic discontinuities among some of the hyperarid areas in Arabia.

Although Stenodactylus includes a relatively low number of species compared to other gecko groups in these areas, such as Pristurus, Tarentola or Hemidactylus [26,41-46], its relatively high level of resource partitioning and habitat specialization has allowed the different species to successfully colonize almost all available habitats in the arid and hyper-arid regions of North Africa and Arabia. It constitutes, therefore, a very interesting, but still poorly studied, genus that makes an excellent model for the study of desert biodiversity and biogeography. The main objectives of the present work are: (1) to provide for the first time a complete phylogeny of the genus Stenodactylus and evaluate its concordance with previous molecular and morphology-based studies; (2) to investigate the biogeographical and diversification patterns of Stenodactylus; and (3) to explore the interspecific relationships, the patterns of intraspecific diversity and the possible presence of unrecognized divergent lineages in Stenodactylus.

\section{Methods}

Taxon sampling, DNA extraction and sequencing

A total of 207 individuals of Stenodactylus representing all twelve currently recognized species were included in 


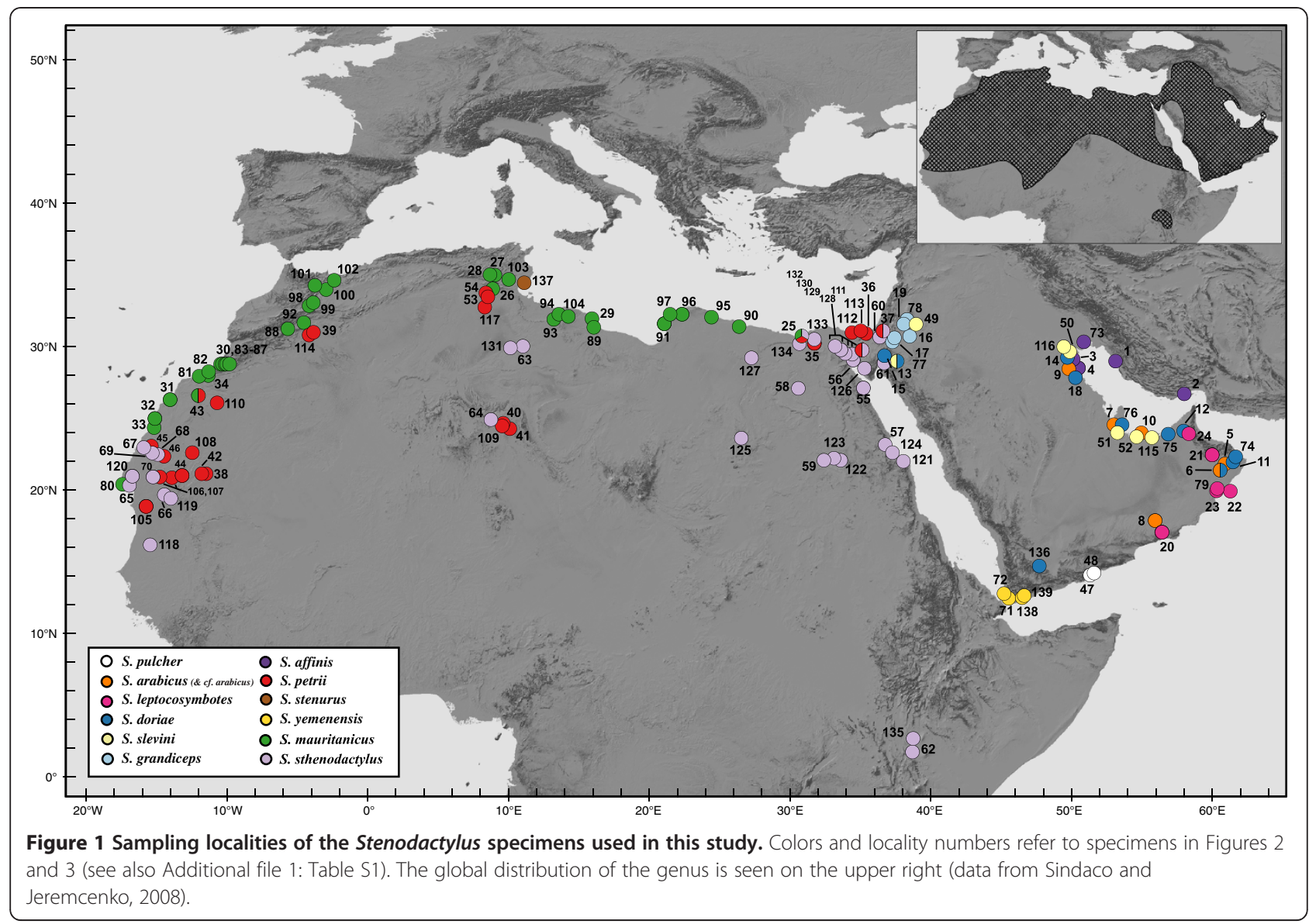

the present study. Whenever possible, we tried to include multiple populations for each species in order to assess intraspecific variation; sampling was especially intense in the three African species with very large distribution ranges. In addition, three Pseudoceramodactylus khobarensis and eight individuals representing six species of the genus Tropiocolotes were included in an attempt to further test the relationship between Stenodactylus, Pseudoceramodactylus and Tropiocolotes. Four additional specimens from other closely related genera [47-49] were used as outgroups and sixteen specimens, from several genera, were added in order to estimate divergence times (see below). Additional file 1: Table S1 lists all 238 samples used in the present work with their extraction codes, voucher references, localities and GenBank accession numbers (KC190516-KC191151).

Genomic DNA was extracted from ethanol-preserved tissue samples using the DNeasy Blood \& Tissue Kit (Qiagen, Valencia, CA, USA). All 222 specimens included in the phylogenetic analyses were sequenced for two mitochondrial gene fragments: 378-388 base pairs (bp) of 12S rRNA (12S) and 498-536 bp of the 16S rRNA (16S). A subset of 106 specimens, including representatives from all independent lineages recovered by the analysis of these two fragments, was also sequenced for two nuclear markers: $660 \mathrm{bp}$ of the oocyte maturation factor MOS (c-mos), and $410 \mathrm{bp}$ of the recombination activating gene 2 (RAG-2). Primers used for the amplification and sequencing of the 12S, 16S, c-mos and RAG-2 gene fragments as well as PCR conditions applied in the present work are listed in detail in Table 1. All amplified fragments were sequenced for both strands. Contigs were assembled in Geneious v.5.3 [50].

\section{Phylogenetic analyses and hypothesis testing}

DNA sequences were aligned using the online version of MAFFT v.6 [51] with default parameters (gap opening = 1.53 , offset value $=0.0$ ) for the mitochondrial genes and with modified parameters (offset value $=0.1$ ) for the nuclear genes, in which long gaps are not expected. Coding gene fragments (c-mos and RAG-2) were translated into amino acids and no stop codons were observed. Uncorrected $p$-distances were calculated in MEGA v.5 [52].

Phylogenetic analyses of the combined dataset were done employing maximum likelihood (ML) and Bayesian (BI) methods. Separate ML analyses were also performed on 12S, 16S, c-mos and RAG-2 to test for conflicting signal among genes. Best-fitting nucleotide substitution models were selected for each partition under the Akaike 
Table 1 Primers used in this study

\begin{tabular}{|c|c|c|c|c|c|}
\hline Gene fragment & Primer name & Or. $^{1}$ & Sequence $\left(5^{\prime}-3^{\prime}\right)$ & Reference & PCR conditions \\
\hline \multirow[t]{4}{*}{$12 S$} & $12 \mathrm{Sa}$ & $\mathrm{F}$ & AAACTGGGATTAGATACCCCACTAT & Kocher et al. (1989) & $94^{\circ}\left(5^{\prime}\right) ; 94^{\circ}\left(45^{\prime \prime}\right), 51^{\circ}\left(45^{\prime \prime}\right), 72^{\circ}\left(80^{\prime \prime}\right) \times 35 ; 72\left(5^{\prime}\right)$ \\
\hline & $12 \mathrm{Sb}$ & $\mathrm{R}$ & GAGGGTGACGGGCGGTGTGT & Kocher et al. (1989) & \\
\hline & L1.STENO & $\mathrm{F}$ & GGATTAGATACCCCACTATGC & This study & $94^{\circ}\left(5^{\prime}\right) ; 94^{\circ}\left(45^{\prime \prime}\right), 52^{\circ}\left(45^{\prime \prime}\right)^{\prime}, 72^{\circ}\left(90^{\prime \prime}\right) \times 35 ; 72^{\circ}\left(5^{\prime}\right)$ \\
\hline & H1.STENO1 & $\mathrm{R}$ & TGACGGGCGGTGTGTACG & This study & \\
\hline \multirow[t]{4}{*}{$16 S$} & $16 \mathrm{Sa}$ & $\mathrm{F}$ & CGCCTGTTTATCAAAAACAT & Palumbi (1996) & $94^{\circ}\left(5^{\prime}\right) ; 94^{\circ}\left(45^{\prime \prime}\right), 51\left(45^{\prime \prime}\right), 72\left(80^{\prime \prime}\right) \times 35 ; 72^{\circ}\left(5^{\prime}\right)$ \\
\hline & $16 \mathrm{Sb}$ & $\mathrm{R}$ & CCGGTCTGAACTCAGATCACGT & Palumbi (1996) & \\
\hline & $16 \mathrm{SaST}$ & $\mathrm{F}$ & ATCAAAAACATCGCCTTTAGC & This study & $94^{\circ}\left(5^{\prime}\right) ; 94^{\circ}\left(45^{\prime \prime}\right), 57^{\circ}\left(45^{\prime \prime}\right), 72^{\circ}\left(70^{\prime \prime}\right) \times 35 ; 72^{\circ}\left(5^{\prime}\right)$ \\
\hline & $16 \mathrm{SbST}$ & $\mathrm{R}$ & CTGAACTCAGATCACGTAGGAC & This study & \\
\hline \multirow[t]{6}{*}{ C-mos } & FUF & $\mathrm{F}$ & TTTGGTTCKGTCTACAAGGCTAC & Gamble et al. (2008) & $94^{\circ}\left(5^{\prime}\right) ; 94^{\circ}\left(30^{\prime \prime}\right), 55^{\circ}\left(45^{\prime \prime}\right), 72^{\circ}\left(70^{\prime \prime}\right) \times 35 ; 72^{\circ}\left(10^{\prime}\right)$ \\
\hline & FUR & $\mathrm{R}$ & AGGGAACATCCAAAGTCTCCAAT & Gamble et al. (2008) & \\
\hline & G73_STENO & $\mathrm{F}$ & GCTGTAAAGCAGGTGAAGAAATGC & This study & $94^{\circ}\left(5^{\prime}\right) ; 94^{\circ}\left(45^{\prime \prime}\right), 56^{\circ}\left(45^{\prime \prime}\right), 72^{\circ}\left(80^{\prime \prime}\right) \times 35 ; 72^{\circ}\left(5^{\prime}\right)$ \\
\hline & G74_STENO & $\mathrm{R}$ & GAACATCCAAAGTCTCCAATCTTGC & This study & \\
\hline & G73.5_STENO & $\mathrm{F}$ & GCATTTGGACTTAAAACCTG & This study & \\
\hline & G708 & $\mathrm{R}$ & GCTACATCAGCTCTCCARCA & Hugall et al. (2008) & \\
\hline \multirow[t]{2}{*}{ RAG-2 } & RAG2-PY1-F & $\mathrm{F}$ & CCCTGAGTTTGGATGCTGTACTT & Gamble et al. (2008) & $94^{\circ}\left(5^{\prime}\right) ; 94^{\circ}\left(45^{\prime \prime}\right), 55^{\circ}\left(45^{\prime \prime}\right), 72^{\circ}\left(70^{\prime \prime}\right) \times 35 ; 72^{\circ}\left(5^{\prime}\right)$ \\
\hline & RAG2-PY1-R & $\mathrm{R}$ & AACTGCCTRTTGTCCCCTGGTAT & Gamble et al. (2008) & \\
\hline
\end{tabular}

List of primers used in the amplification and sequencing of gene fragments, with the corresponding source and PCR conditions.

${ }^{1}$ Orientation.

information criterion [53] using jModelTest v.0.1.1 [54]. The GTR + I + G model was independently estimated for each of the 12S, 16S, RAG-2 partitions and the GTR + G model for the c-mos partition. Alignment gaps were treated as missing data and the nuclear gene sequences were not phased. Hemidactylus frenatus was used for rooting the tree, based on published evidence $[47,48]$.

A Bayesian analysis of the combined dataset was performed in MrBayes 3.1.2 [55,56] with best fitting models applied to each partition (gene) and all parameters unlinked across partitions. Analyses ran for $10^{7}$ generations, with sampling intervals of 1000 generations, producing 10000 trees. Convergence and appropriate sampling were confirmed examining the standard deviation of the split frequencies between the two simultaneous runs and the Potential Scale Reduction Factor (PSRF) diagnostic. Burn-in was performed discarding the first 2500 trees of each run and a majority-rule consensus tree was generated from the remaining trees. ML analyses were performed in RAxML v.7.0.3 [57]. A GTR + I + G model was used and parameters were estimated independently for each partition. Node support was assessed by bootstrap analysis [58] including 1000 replications.

Haplotype networks were constructed for the two nuclear markers c-mos and RAG-2. The software PHASE v.2.1.1 $[59,60]$ was used to resolve the haplotypes where more than one heterozygote position was present. Input files were prepared using Seqphase [61]. In order to include as much information as possible for the better resolution of the haplotypes, the alignment of all fulllength sequences of each marker was used. Phase probabilities parameter was set at 0.7 and all other settings were set by default. The network of the resulting haplotypes was calculated with TCS v.1.21 [62] applying default settings (probability of parsimony cutoff: 95\%).

Topological constraints to test alternative topologies were constructed by hand and compared to the unconstrained (best) tree using the Approximately-Unbiased (AU) [63] and Shimodaira-Hasegawa (SH) [64] tests. Per-site log likelihoods were estimated in RAxML 7.0.3 [57] and $P$-values were calculated using CONSEL [65]. Tests were also run in a Bayesian framework, where the relative support of competing hypotheses given the data was quantified using the Bayes factor (BF) [66]. Topologies were constrained in analyses run in BEAST v.1.6.1 [67], the marginal likelihood for each topology was estimated using the harmonic mean estimator and the Bayes factors were calculated by taking the ratios, as estimated in Tracer v.1.5 [68].

\section{Estimation of divergence times}

A Bayesian approach was used to estimate divergence times as implemented in the software BEAST v.1.6.1. The dataset comprised sequences from all four partitions (the nuclear genes c-mos and RAG-2 unphased). An arbitrarily pruned phylogeny was used in order to include only one representative from each species or main lineage uncovered with the concatenated analysis (45 specimens in total; see Additional file 1: Table S1). This method excludes closely related terminal taxa because the Yule tree prior does not include a model of coalescence, which can complicate rate estimation for closely related 
sequences [69]. Additionally, several taxa belonging to other gecko genera were added for the calibration process (see below).

Two individual runs were performed for $4 \times 10^{7}$ generations with a sampling frequency of 4000 and the results were combined to infer the ultrametric tree after discarding $10 \%$ of the samples from each run. Models and prior specifications applied were as follows (otherwise by default): GTR + I + G (12S, 16S), GTR + I (c-mos), HKY + I (RAG-2); Relaxed Uncorrelated Lognormal Clock (estimate); Yule process of speciation; random starting tree; alpha Uniform $(0,10)$; yule.birthRate $(0,1000)$. Parameter values both for clock and substitution models were unlinked across partitions.

Unfortunately, no fossils belonging to Stenodactylus, Pseudoceramodactylus or Tropiocolotes are known, precluding the direct estimation of the time of the cladogenetic events within our study group. Consequently, the estimation was based on well-known calibration points published in recent literature [70,71] related to members of the families Phyllodactylidae and Sphaerodactylidae (see Additional file 1: Table S1). Three fossil and biogeographical calibration points were applied as "soft" priors, in order to account for uncertainty in the date of the corresponding nodes: (1) the minimum age for the divergence between Euleptes and its sister clade was set to $22.5 \mathrm{Ma}$ ago using the approximate age of a fossil Euleptes [72,73] (Lognormal distribution: median 22.5, 97.5\% 36.55); (2) the split between Teratoscincus scincus - Teratoscincus roborowskii caused by the Tien Shan-Pamir uplift $10 \mathrm{Ma}$ ago [74-76] (Lognormal distribution: median 10.08, 97.5\% 12.96); (3) the age of El Hierro island [77] at $1.12 \mathrm{Ma}$ ago, assuming that divergence between Tarentola boettgeri hierrensis and Tarentola boettgeri bischoffi began soon after its appearance [26,44] (Uniform distribution: lower 1, upper 1.12). In order to cross-check the results, the posterior mean rates of the mitochondrial gene fragments of our analysis were compared to the rates calculated for well-known and well-studied reptile groups from the Canary Islands (the geckos of the genus Tarentola, the lacertid lizards of the endemic genus Gallotia and the skinks of the genus Chalcides), for which robust calibrated phylogenies have been produced in several independent analyses ([26,45,78-80], among others), and evolutionary rates for the $12 \mathrm{~S}$ gene have been obtained using BEAST [44].

\section{Ancestral area reconstruction}

MacClade v. 4.08 [81] was used to reconstruct the ancestral areas for the Stenodactylus species in a parsimony framework, using both delayed transformation (DELTRAN) and accelerated transformation (ACCTRAN). Additionally, in order to incorporate branch-length information, ML was used as implemented in the Mesquite software package
[82]. Both Markov k-state 1-parameter and Asymmetrical Markov k-state 2-parameter models were applied and a likelihood ratio test was used to choose the best reconstruction. Two states, Arabia and Africa, were identified in the extant species depending on the present distribution of the species [33] and were used with both methodologies.

\section{Results \\ Phylogenetic analyses and topological tests}

Two datasets were used to infer the phylogenetic relationships of the genus Stenodactylus: a mitochondrial one for building the preliminary phylogeny and analyzing the divergence patters, and a multi-locus one for producing a more robust phylogeny (TreeBASE ID: 13567). The first dataset consisted of an alignment of 974 bp of mitochondrial DNA (415 bp of $12 \mathrm{~S}$ and $559 \mathrm{bp}$ of $16 \mathrm{~S}$, of which 270 in both cases were variable positions) for 222 terminals including 207 Stenodactylus. The results of the ML and BI of this dataset were very similar and are summarized in Supplementary Figure 1 (Additional file 2: Figure S1). In order to improve our phylogenetic hypothesis applying a multi-locus approach, a second dataset was assembled with a selection of 106 terminals, including 91 Stenodactylus (see Additional file 1: Table S1) for which two extra nuclear genes were sequenced. The aligned dataset consisted of 2092 bp (419 bp of 12S, 560 bp of 16S, 703 bp of c-mos and 410 bp of $R A G-2$, of which 262, 269, 109 and 99 positions were variable, respectively). The result of the phylogenetic analyses of the concatenated alignment of four genes is shown in Figure 2. Well-supported relationships in the independent gene trees were congruent among partitions, but at this level not all markers offered sufficient resolution to differentiate particularly between $S$. sthenodactylus and S. mauritanicus (data not shown but see below). The networks constructed for the phased haplotypes of the nuclear markers are presented in Figure 3. Not all ambiguities were resolved.

Both ML and Bayesian analyses of the concatenated alignment of four gene fragments (Figure 2) gave almost identical results to the mtDNA tree from the Additional file 2: Figure S1 There is low support over the relationships between the genera Stenodactylus, Pseudoceramodactylus and Tropiocolotes. According to the results, the North African T. algericus and T. tripolitanus branch first and $P$. khobarensis is sister to a poorly supported clade formed by two reciprocally monophyletic groups: one including T. scorteccii, T. steudneri, T. nubicus and the Middle Eastern T. nattereri and the other one including all 12 species of the genus Stenodactylus. In order to further investigate these relationships, three topological tests were carried out: (1) Stenodactylus + Pseudoceramodactylus were forced 


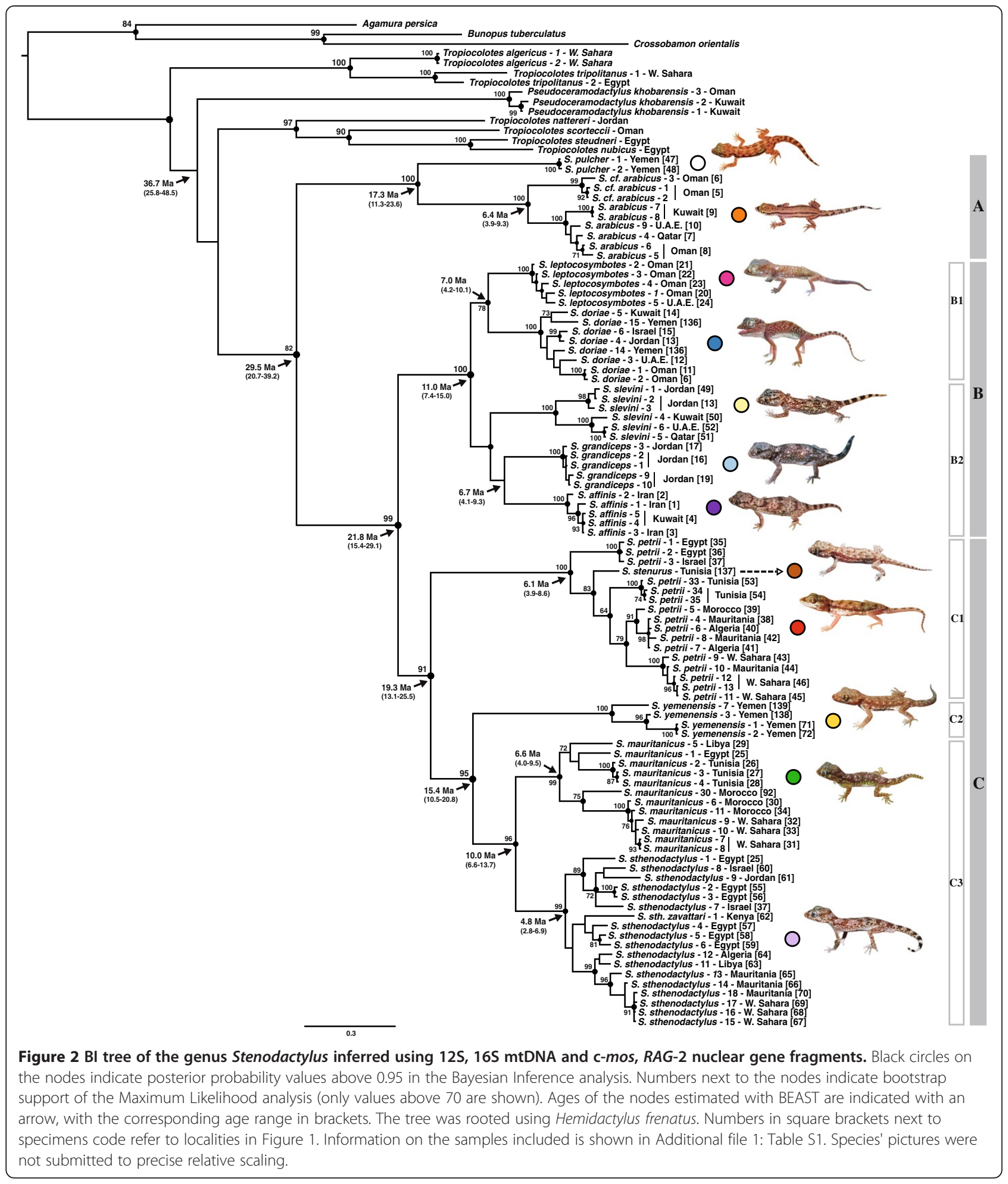

monophyletic; (2) Tropiocolotes was forced monophyletic; and (3) Stenodactylus + Pseudoceramodactylus were forced monophyletic and Tropiocolotes was forced monophyletic on the same constraint tree. The resulting constrained topologies were compared to our optimal topology from Figure 2 under both ML and Bayesian frameworks (see Table 2). The results of the topological tests indicate that our dataset cannot reject the alternative hypothesis of monophyly of Stenodactylus + Pseudoceramodactylus (AU:0.461, SH:0.839, BF:0.647), monophyly of Tropiocolotes 

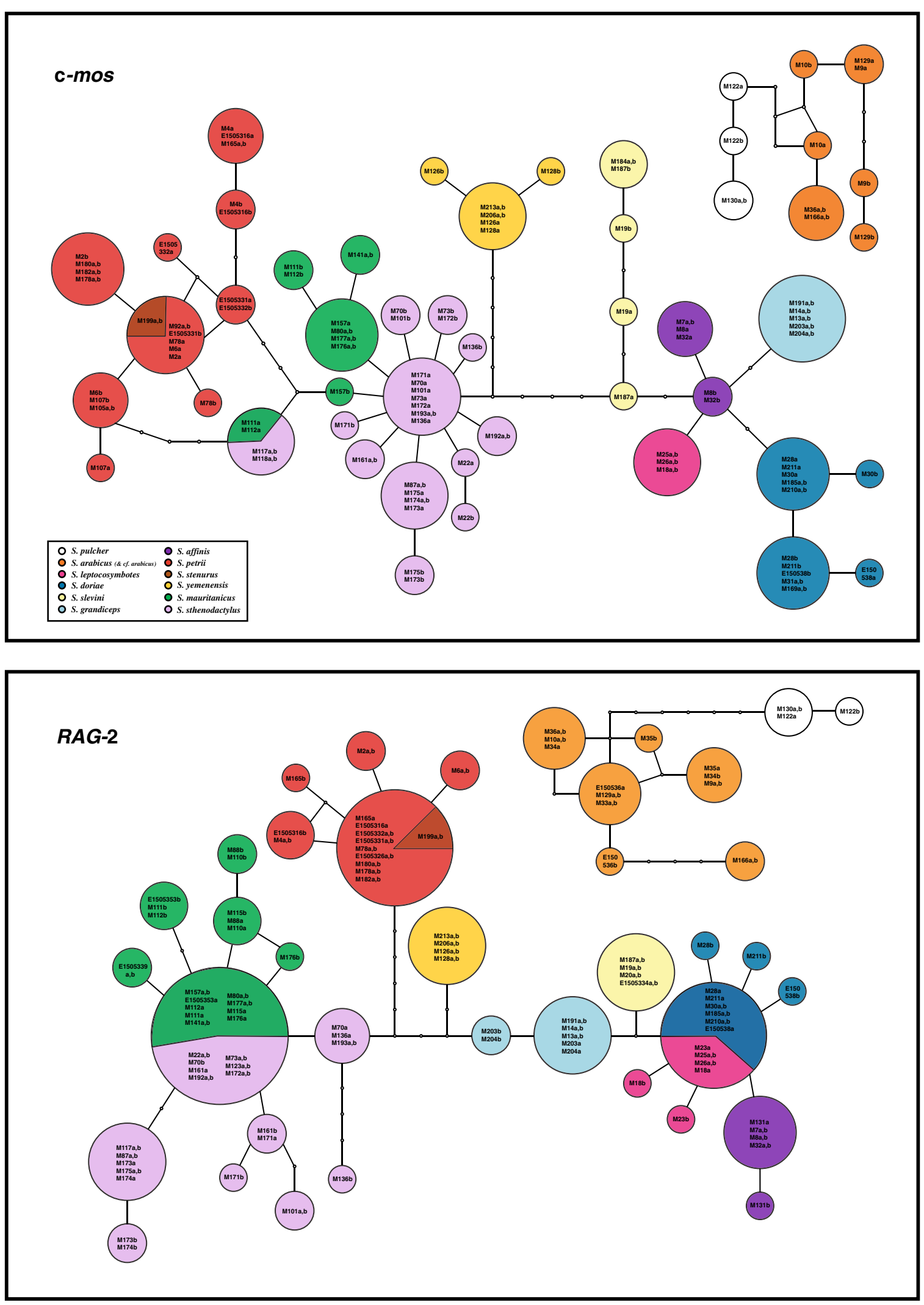

Figure 3 Haplotype networks of the nuclear markers c-mos and RAG-2. Only full-length sequences were used and phase probabilities were set as $\geq 0.7$. Information on the samples included is shown in Additional file 1: Table S1. 
(AU:0.161, SH:0.495, BF:-0.530) or both concurrently (AU:0.153, SH:0.492, BF:1.589).

Within Stenodactylus, three well supported clades are revealed (see Figure 2): (i) clade A, formed by the Arabian species S. pulcher Anderson, 1896 [36], S. arabicus and the divergent lineage $S$. cf. arabicus, (ii) clade B, that includes five Arabian species (S. leptocosymbotes Leviton and Anderson, 1967 [83], S. doriae, S. slevini Haas, 1957 [37], S. grandiceps Haas, 1952 [84] and S. affinis (Murray, 1884) [85] grouped in 2 sub-clades, and (iii) clade $C$, formed by the four African species (S. petrii, S. stenurus Werner, 1899 [86], S. mauritanicus Guichenot, 1850 [87] and S. sthenodactylus (Lichtenstein, 1823) and the southwest Arabian endemic S. yemenensis Arnold, 1980 [31].

Clade A is sister to the remaining species of the genus and includes the two morphologically similar but highly divergent species $S$. pulcher and $S$. arabicus ( $p$-distance 12S: $12.5 \%$ and 16S: 14.5\%) (Additional file 3: Table S2a). Genetic variability within $S$. arabicus is very high and includes two reciprocally monophyletic deep lineages (p-distance 12S: $7.7 \%$ and 16S: 5.0\%) (Additional file 3: Table S2c), one of them restricted to the Sharqiya Sands (formerly Wahiba Sands) in Oman, hereafter referred to as $S$. cf. arabicus, and the other one covering the rest of the distribution range of the species. Network analysis of the nuclear gene fragments $c$-mos and RAG-2 shows that for the former all alleles are unique for each lineage and all but one for the latter (Figure 3).

Clade B is well supported and groups $S$. doriae and S. leptocosymbotes in sub-clade B1, while S. slevini, S. grandiceps and S. affinis in B2. Phylogenetic relationships are not completely resolved in the latter. Genetic distances between these five species are among the lowest in the genus (Additional file 3: Table S2a). Nuclear network analyses (Figure 3) reveal only unique alleles in the $c$-mos gene fragment for all five species, while there is some allele sharing in RAG-2 between $S$. doriae and S. leptocosymbotes.
Finally, clade $\mathrm{C}$ consists of three sub-clades, two African and one Arabian. The North African sub-clade C1 braches first, and the Arabian S. yemenensis is sister to sub-clade C3 formed by the two North African species S. mauritanicus and S. sthenodactylus, making the group of North African Stenodactylus species paraphyletic. Topological constraint analyses indicate that the alternative hypothesis of monophyly of the North African species is rejected by the AU and BF tests (AU:0.029, SH:0.123, BF:7.221) (Table 2).

In sub-clade C1, S. stenurus is nested within S. petrii, rendering the latter paraphyletic. The results of the topological constraint analysis in which $S$. petrii was forced monophyletic show that this hypothesis is rejected by both $\mathrm{AU}$ and BF tests (AU:0.036, SH:0.210, BF:2.578) (Table 2). Network analysis shows that $S$. stenurus lacks unique alleles in both nuclear markers (Figure 3). The level of intraspecific genetic variability within S. petrii (Additional file 3: Table S2b) is very high: the uncorrected $p$-distances between specimens from Egypt and Israel, and the remaining $S$. petrii specimens sampled for this study is $7.2 \%$ and $6.0 \%$ for the $12 \mathrm{~S}$ and $16 \mathrm{~S}$ mitochondrial markers, respectively (Additional file 3: Table S2c). Nuclear networks indicate that all six c-mos and four out of six RAG-2 alleles investigated are unique to this former lineage of $S$. petrii (Figure 3).

In sub-clade C3, the two North African species $S$. sthenodactylus and $S$. mauritanicus are reciprocally monophyletic and highly divergent ( $p$-distance $12 S: 10.9 \%$ and 16S: 7.2\%) (Additional file 3: Table S2a). The former is highly variable ( $p$-distance: $12 \mathrm{~S} \quad 4.7 \%$ and $16 \mathrm{~S} 3.2 \%$ ) (Additional file 3: Table S2b) and presents three deep lineages that follow a clear geographical pattern (Figures 1 and 2), grouping animals from: 1.- northern Egypt, Israel and Jordan; 2.- south, southeast Egypt and Kenya; 3.- all the animals from Libya, Algeria, Tunisia, Western Sahara and Mauritania, although a single specimen from NE Egypt (loc. 127 in Figure 1, Siwa Oasis) is also part of this

Table 2 Statistical support for alternative hypotheses on Stenodactylus phylogeny

\begin{tabular}{|c|c|c|c|c|c|}
\hline \multirow[b]{2}{*}{ Tree } & \multirow[b]{2}{*}{-log likelihood } & \multicolumn{2}{|c|}{ ML framework ${ }^{1}$} & \multicolumn{2}{|c|}{ Bayesian framework ${ }^{2}$} \\
\hline & & $\mathrm{AU} P$ & SH $P$ & HME & $\log _{10} B F$ \\
\hline Unconstrained tree & 15180.095955 & & & -15175.4907 & \\
\hline Monophyly of Stenodactylus+Pseudoceramodactylus & 15180.877129 & 0.461 & 0.839 & -15175.0633 & 0.647 \\
\hline Monophyly of Tropiocolotes & 15183.765511 & 0.161 & 0.495 & -15175.6215 & -0.530 \\
\hline Monophyly of Stenodactylus+Pseudoceramodactylus and Tropiocolotes & 15183.696084 & 0.153 & 0.492 & -15177.9132 & 1.589 \\
\hline Monophyly of African species & 15192.711115 & 0.029 & 0.123 & -15190.3457 & 7.221 \\
\hline Monophyly of S. petrii & 15189.220967 & 0.036 & 0.210 & -15181.4116 & 2.578 \\
\hline
\end{tabular}

All topological tests are done versus the unconstrained (best) tree. Values in bold indicate statistically significant results.

${ }^{1}$ ML: Maximum likelihood; AU: Approximately Unbiased test (Shimodaira, 2002); SH: Shimodaira \& Hasegawa (1999) test. $P<0.05$ suggests that the two solutions are significantly different.

${ }^{2} \mathrm{HME}$ : The harmonic mean of sampled likelihoods as estimated by Tracer. BF: Bayes Factor. A $\log _{10}$ Bayes factor $>2$ indicates decisive evidence for statistically significant difference between solutions. 
latter clade. The results of the network analyses also show a differentiation between these three lineages. In c-mos (Figure 3), in the first lineage 7 out of 10 alleles are unique, in the second lineage 2 out of 6 and in the third lineage 9 out of 16, while in RAG-2, 3 out of 10, 2 out of 8 and 10 out of 12 are unique, respectively (Figure 3 ). Genetic variability within $S$. mauritanicus is slightly higher than in S. sthenodactylus ( $p$-distance: 12S 4.7\% and $16 \mathrm{~S} 4.3 \%$ ) (Additional file 3: Table S2b) and six different mitochondrial lineages with geographic structure are found: 1.- easternmost part of Libya and Egypt; 2.- central Libya; 3.- Tunisia; 4.- Northern Morocco; 5.- two very divergent samples from southeastern Morocco; and 6.- all the southern Morocco plus Western Sahara samples (see Figure 1 and Additional file 2: Figure S1).

\section{Estimation of divergence times}

Convergence was confirmed examining the likelihood and posterior trace plots of the two runs with Tracer v.1.5. Effective sample sizes of the parameters were above 200, indicating a good representation of independent samples in the posterior. The estimated divergence times are illustrated in Figure 2 and the chronogram can be seen in Supplementary Figure 2 (Additional file 4: Figure S2). Diversification within Stenodactylus initiated 29.5 Ma ago (95\% HPD: 20.7-39.2). In clade A, the split between $S$. pulcher and $S$. arabicus is dated back to 17.3 Ma (95\% HPD: 11.3-23.6). The separation between the ancestors of clades $\mathrm{B}$ and $\mathrm{C}$ dates back to $21.8 \mathrm{Ma}$ (95\% HPD: 15.4-29.1), while diversification within these two clades started 11.0 Ma (95\% HPD: 7.4-15.0) and 19.3 Ma (95\% HPD: 13.1-25.5) ago, respectively.

Posterior mean rates for the $12 \mathrm{~S}$ and $16 \mathrm{~S}$ mitochondrial gene fragments were estimated at 0.00701 and 0.00642 substitutions per lineage per million years, respectively (or divergence rate: $1.402 \%$ and $1.284 \%$ ). The posterior rates for the nuclear fragments, c-mos and RAG-2, were 0.00052 and 0.00060 respectively, more than 10 times lower than the mitochondrial ones. The $12 \mathrm{~S}$ mitochondrial rate concords extremely well with the average rate for the same mitochondrial gene for three Canary Island reptile groups (Gallotia, Tarentola and Chalcides; 0.00755 for the $12 \mathrm{~S}$ gene) as estimated by Carranza and Arnold (2012) [44].

\section{Ancestral area reconstruction}

Reconstruction of the ancestral areas of Stenodactylus species was done in a parsimony framework based on the topology of the phylogeny presented in Figure 2. The analysis indicates that the reconstruction of the area for some of the ancestors is equivocal (see Figure 4). These are the common ancestor of clade $\mathrm{C}$, formed by all North African species and $S$. yemenensis, and the ancestor of the latter and the sister species S. sthenodactylus/
S. mauritanicus. Reconstructions using accelerated transformation (ACCTRAN) or delayed transformation (DELTRAN) optimizations support an identical number of events involving Arabia and Africa, but the direction of events is different. ML-based reconstruction, considering branch-length information, with the best-fit Markov k-state 1-parameter model also provided results with fairly similar probabilities for the two states in the aforementioned nodes (Figure 4).

\section{Discussion}

This constitutes the first phylogenetic study using a complete sampling of Stenodactylus taxa and including 207 specimens from across the entire distribution range of North Africa and Arabia (Figure 1). This has enabled a robust phylogenetic reconstruction (see Figure 2 and Additional file 2: Figure S1), the uncovering of intraspecific diversity and, in some cases, the unveiling of interesting distribution patterns (see below). The phylogenetic results show a high level of support in most of the nodes and a striking agreement with the phylogenetic analyses of Stenodactylus by Arnold (1980) [31], based on morphological data, increasing our confidence that the recovered topology represents the true evolutionary history of the genus.

\section{Monophyly of Stenodactylus}

Despite the general concordance between morphological and phylogenetic conclusions, one important discrepancy is observed: while morphology supports the inclusion of P. khobarensis in the genus Stenodactylus, the results of our molecular analyses indicate that Pseudoceramodactylus and Stenodactylus are not even sister genera (Figure 2). Kluge (1967) [39] transferred P. khobarensis to the genus Stenodactylus based on a "large number of external (meristic and mensural) and internal morphological similarities", including relevant characters like the phalangeal reduction to a formula of 2.3.3.4.3 on both fore and hind limbs and a very high scleral ossicle number (20-28). Arnold (1980) [31], despite pointing out some unique scale characters of P. khobarensis, retained it in Stenodactylus and considered the scalation characters as "convincing pointers to holophyly". However, according to a recent molecular analysis of the group by Fujita and Papenfuss (2011) [40] based on independent samples and sequences of different mitochondrial and nuclear regions, two representatives of Tropiocolotes branched between $P$. khobarensis and the six species of Stenodactylus included in the analysis (see Figure 1 of [40]). In order to deal with the non-monophyly of Stenodactylus, the genus Pseudoceramodactylus was resurrected. This pattern is repeated and further investigated in our study, with a complete taxon sampling of Stenodactylus and the inclusion of a greater number of representatives of Tropiocolotes, 


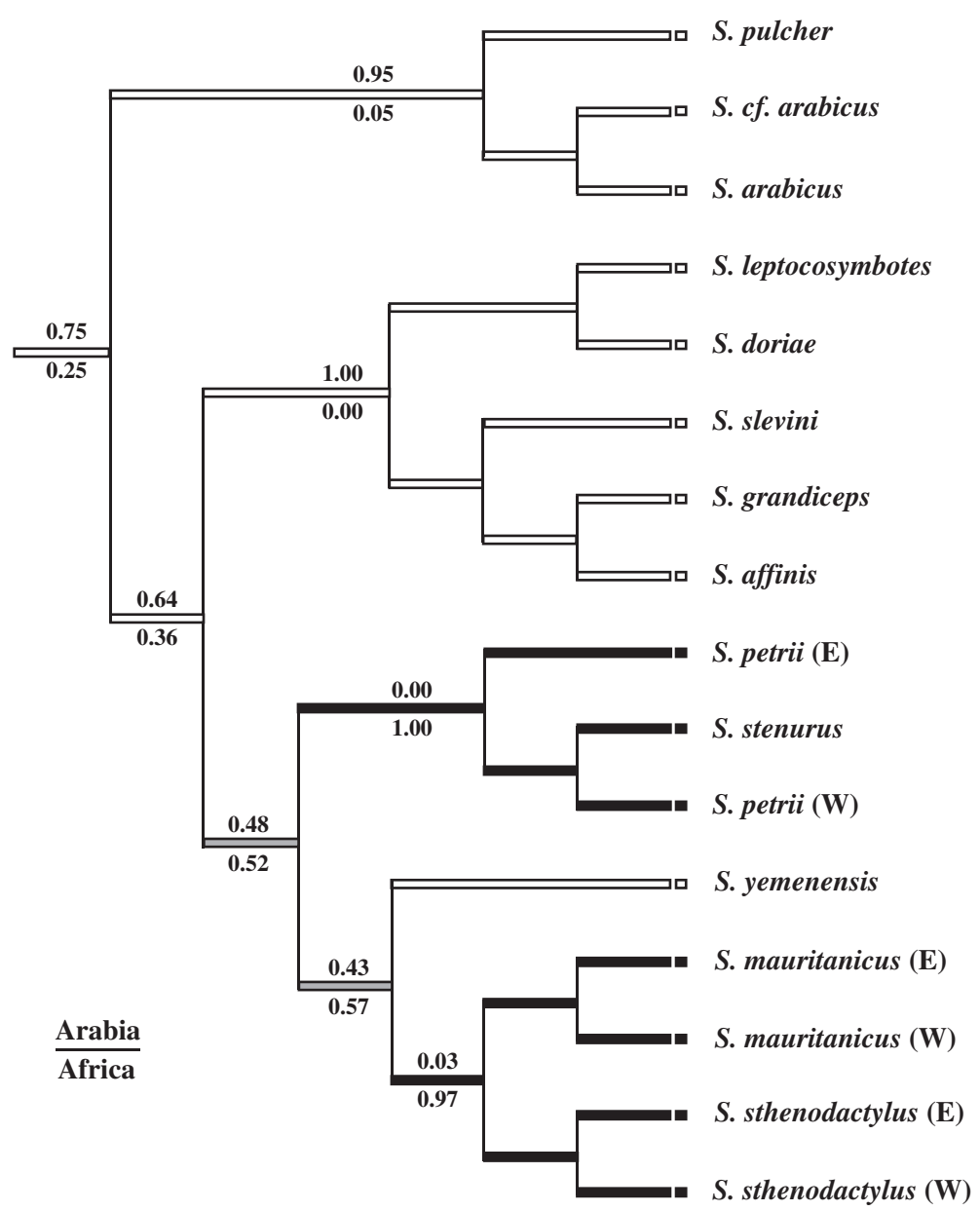

Figure 4 Ancestral area reconstruction. The tree figure illustrates the parsimony reconstruction, while numbers above and below nodes correspond to ML probabilities for character states. Black and white colors correspond to Africa and Arabia respectively, and grey color indicates equivocal nodes.

resulting in the splitting of the latter genus into two groups, a surprising but not strongly supported, albeit consistent, result.

We performed a series of constraint analyses in which Stenodactylus and Pseudoceramodactylus were forced to form a monophyletic group. Results clearly show that our dataset cannot reject the alternative hypothesis of a monophyletic Stenodactylus + Pseudoceramodactylus group (Table 2). In order to further investigate this, the dataset of Fujita and Papenfuss (2011) [40] was subjected to the same ML topological tests, but also could not reject the alternative hypothesis of monophyly of Stenodactylus + Pseudoceramodactylus (AU $P=0.074$; SH $P=0.092$ ). In view of the confusing molecular evidence and taking into account the morphological data, we think that the resurrection of Pseudoceramodactylus was precipitated, but in the meanwhile, this change accommodates for both the paraphyly reported by Fujita and Papenfuss and confirmed here, and the hypothesis of monophyly of Stenodactylus + Pseudoceramodactylus. We recommend not performing any further changes at the generic level before an in-depth revision clarifies the evolutionary relationships between the genera Stenodactylus, Pseudoceramodactylus and Tropiocolotes.

\section{Systematics and evolution}

The well-supported clade A is formed by the morphologically similar S. pulcher, S. arabicus and the lineage $S$. cf. arabicus and, according to the inferred dates, the split between the former and the two latter species dates back to approximately $17 \mathrm{Ma}$ ago (95\% HPD: 11.3-23.6) (Figure 2). On the one hand, variability within $S$. pulcher is very low, probably as a result of the two specimens analyzed being from very close localities. On the other hand, the $S$. cf. arabicus lineage from the Sharqiya Sands (formerly Wahiba Sands), as already highlighted by Fujita and Papenfuss (2011) [40], is genetically very distinct from all other 
populations of $S$. arabicus included in our study in both mitochondrial and nuclear markers (Additional file 3: Table S2c and Figure 2), where almost all alleles are lineage-specific (see Results and Figure 3). This supports the idea that the Sharqiya Sands are isolated and surrounded by some areas of unsuitable habitat for sand dune specialists like this species [88-90]. Further morphological and molecular studies including more specimens from putative contact zones and faster nuclear markers are expected to give $S$. cf. arabicus formal recognition.

Clade B is well-supported (ML 100\%, BI 1.0) and was also recovered by the morphological analysis of Arnold (1980) [34]. Stenodactylus doriae and S. leptocosymbotes are reciprocally monophyletic and form the relatively well-supported sub-clade B1 (Figure 2). Our molecular results agree with the results of the morphological analysis by Arnold (1980) [31], who also recovered the two species as sister taxa based on three synapomorphies. The two species diverged approximately 7.0 Ma ago (95\% HPD: 4.2-10.1) (Figure 2) and, like the two North African sister species S. sthenodactylus and S. mauritanicus, they are ecologically distinct. Stenodactylus leptocosymbotes is an arid-adapted species that lives on relatively hard, although usually sandy, substrates being replaced by its sister species, $S$. doriae, on soft, wind-blown sand [34,91]. Thanks to its morphological and physiological adaptations, the latter is able to live in hyper-arid sand dune environments like for example the Eastern Rub al Khali [92], one of the largest and driest sand deserts in the world [93]. Given the clear morphological and ecological differences between these two species and the apparent absence of morphologically intermediate individuals $[31,34]$, it seems reasonable to deduce that allele sharing in RAG-2 (see Results), which is limited to the ancestral allele, is the result of incomplete lineage sorting rather than ongoing gene flow between the two species. Variability within S. leptocosymbotes is rather low (Additional file 3: Table S2b) and the number of samples included permit to observe only moderate geographical structuring (Figures 1 and 2, Additional file 2: Figure S1). In contrast, $S$. doriae, shows a higher level of genetic differentiation, with the Sharqiya Sands lineage being quite divergent (Additional file 3: Table S2c and Figure 2), as already mentioned by Fujita and Papenfuss (2011) [40].

Sister to sub-clade B1 is a group composed by S. slevini, $S$. grandiceps and $S$. affinis, for which support is relatively low (ML 62, BI = 0.95). The topology within this sub-clade differs from the morphological hypothesis of Arnold (1980) [34], which supported the following relationship: (S. grandiceps (S. affinis (S. slevini (S. leptocosymbotes, $S$. doriae)))). Stenodactylus slevini is the only member of the group with two divergent lineages, one limited to Jordan and the other with representatives from East Arabia. Although the divergence based on mi- tochondrial data is clear (Additional file 2: Figure S1), there is no supporting nuclear data available (Figure 3), and no obvious morphological differences (pers. obs.). With the only exception of the soft wind-blown sand specialist $S$. doriae, all remaining representatives of clade B plus two other species, the African $S$. sthenodactylus and the Arabian S. yemenensis, appear to occupy rather similar spatial niches. These six species are adapted to living on relatively hard ground, coarse sandy planes, large wadis and sandy substrates and, based on their head dimensions, probably feed on similar-sized prey $[31,32,34]$. As a consequence of that, these species rarely coexist and have largely allopatric distribution ranges, while in places where they coincide they are not syntopic [31,33,34]. The analysis of the nuclear allele networks (Figure 3) indicate that the morphologically and ecologically similar and phylogenetically closely related $S$. leptocosymbotes, S. slevini, $S$. grandiceps and $S$. affinis do not share a single allele in the c-mos and RAG-2 genes analyzed, even though the results of the calibration analyses suggest that $S$. grandiceps and $S$. affinis diverged later (6.7 Ma ago; 95\% HPD: 4.19.3) than other lineages for which extensive allele sharing in the $R A G-2$ has been identified ( $S$. doriae and S. leptocosymbotes; see above and Results). These differences of the level of lineage sorting in some of the morphologically well-recognized species may also be the result of differences in effective population sizes, which affect the lineage coalescence time [94].

In sub-clade $C 1, S$. petrii is grouped together with the North African endemic S. stenurus that branches inside it (Figure 2). As a result, $S$. petrii is paraphyletic and constitutes the only exception among the otherwise monophyletic Stenodactylus species. The results of the topological tests (Table 2) indicate that our dataset most probably rejects the monophyly of this species (AU:0.036, SH:0.210, BF:2.578). Stenodactylus stenurus was described by Werner (1899) [86] and synonymized ten years later by the same author [95]. It remained in synonymy until Kratochvil et al. (2001) [96] recognized it as a valid species, based on a multivariate analysis of several metric and scalation characters. It is noteworthy that the representative of $S$. stenurus included in our analysis is one of the specimens used by Kratochvil et al. (2001) [96] in their study.

The highly divergent lineage that includes specimens from Egypt and Israel (see Results) is estimated to have split from specimens further west in Algeria, Morocco, Western Sahara and Mauritania approximately 6.1 Ma ago (95\% HPD: 3.9-8.6) (Figure 2). In fact, the northern Sinai populations of $S$. petrii have been reported to be morphologically distinct and, as a result of that, were considered a different species (S. elimensis) by Barbour (1914) [97], now under the synonymy of S. petrii [31,98]. Yet, specimens from this area included in our analyses 
do not present considerable genetic differences with the rest of the Egyptian and Israeli specimens (Figures 1 and 2, Additional file 2: Figure S1). It should be pointed out that the type locality of $S$. petrii is Egypt and, thus, this lineage represents the 'true' $S$. petrii. The pattern in the nuclear genes, with numerous unique alleles for this lineage (Figure 3), contrasts with the situation in S. stenurus that lacks unique alleles. This suggests that further analyses and a thorough taxonomic revision including more samples of $S$. petrii, especially from not sampled areas of Algeria and Libya, and mainly S. stenurus will be necessary in order to evaluate the status of the populations assigned to the two species. With this evidence it will be possible to differentiate between a single species with high genetic variability (petrii), two species (petrii in the East and stenurus in the West) or three species, if stenurus proves to be distinct from the more western forms.

The two North African species of sub-clade C3, S. sthenodactylus and S. mauritanicus, are shown to be reciprocally monophyletic and highly divergent (Additional file 3: Table S2a), while their separation dates back to approximately 10.0 Ma (95\% HPD: 6.6-13.7) (Figure 2). These results help to clarify the status of these two taxonomically controversial taxa that were treated as two different subspecies by Loveridge (1947) [99] and Sindaco and Jeremcenko (2008) [33], as the same monotypic species by Arnold (1980) [31] and that were finally considered as full species by Baha el Din (2006) [98], who found them in sympatry at particular localities in northern Egypt. As observed by Baha el Din (2006) [98], although these two sister species can be morphologically similar and share similar habits, they are ecologically different. Stenodactylus mauritanicus is restricted to fairly mesic coastal semi-desert under the influence of the Mediterranean (see Figure 1), where it inhabits flat rock-strewn sand and gravel plains with fairly good vegetation cover. On the contrary, S. sthenodactylus inhabits areas of the Sahara that are far more arid and inhospitable than the ones of its sister species (see Figure 1), being the only vertebrate to be readily found in some parts of the Western Desert of Egypt [98]. It prefers gravelly and coarse sandy plains and large wadis and, although the species is typical of hard coarse substrates, it sometimes penetrates some dune areas [98].

The distributions of these two species, as introduced by the present study, give insights into the controversial taxonomic status and frequent misidentification of the two forms [99]. Our analysis concludes that S. sthenodactylus extends west from the Middle East and Egypt, previously thought to be its eastern limit, across the Sahara and into Mauritania (Figure 1). Stenodactylus mauritanicus is confirmed to be present in Egypt [98] and has a wide, almost continuous distribution roughly along the northern margin of the Sahara desert. The two species are found in sympatry or in close proximity in Egypt and coastal Mauritania, yet retain distinct mtDNA lineages and exhibit only limited allele sharing in the nuclear markers, most of which is due to sharing of ancestral alleles and hence is likely to represent incomplete lineage sorting (see Figure 3).

Stenodactylus sthenodactylus presents high variability, both at genetic (see Results) and morphological levels [31]. Its three deep lineages are estimated to have diverged approximately 4.8 Ma ago (95\% HPD: 2.8-6.9) (Figure 2). According to Baha el Din (2006) [98], some morphological characters appear to correlate with environmental factors, with populations from hyper-arid places showing a very slender body, less contrasting pattern and tubular nostrils, while populations from more mesic areas being usually more robust, with thick limbs, big heads and marked pattern $[31,36,98]$. The populations from coastal regions in southeast Egypt are especially distinct and, according to Baha el Din (2006) [98], they resemble specimens of $S$. s. zavattarii from Kenya, which Loveridge (1957) [100] synonymized with S. sthenodactylus. Two specimens of this form were included in our phylogenetic analyses (see Figure 2 and Additional file 2: Figure S1), and indeed they belong to a clade with samples from south and southeast Egypt. These results suggest that some of the morphological variability between populations of S. sthenodactylus may also be supported by molecular data. A nomenclatural revision of North African Stenodactylus (work in progress) is essential for stability before any changes are performed, while further work focused on the contact zones between the three lineages and combining detailed morphological analyses with additional nuclear data is needed in order to determine if they deserve formal recognition.

On the other hand, the high genetic variability within $S$. mauritanicus (Figure 2 and Additional file 3: Table S2b) does not seem to correlate with differences in morphology. This species is fairly uniform morphologically, with populations from the West being a bit larger than Egyptian ones but generally maintaining the same proportions, pattern and scalation across most of its distribution range [98]. Nevertheless, the intra-specific divergence is estimated to date back to 6.6 Ma ago (95\% HPD: 4.0-9.5) and the six mitochondrial lineages present a clear geographical pattern (Figure 1 and Additional file 2: Figure S1). The relationship between these lineages, however, is not clear and neither is any structure observed in the nuclear alleles (Figure 3), both facts being mirrored in the lowsupported nodes of the concatenated phylogeny (Figure 2).

\section{Origin, biogeography and diversification of Stenodactylus}

Reconstruction of ancestral areas with both parsimony and ML methods (Figure 4) suggests that the genus Stenodactylus originated in Arabia approximately 
30 Ma ago (95\% HPD: 20.7-39.2) (Figure 2), a time of high geological instability as a result of the onset of major seismic and volcanic events in the general area of Ethiopia, northeast Sudan and southwest Yemen [101]. These major volcanic and tectonic events, centered over the Afar region, marked the onset of the formation of some of the most relevant and complex physiographical features in the contact zone between Africa and Arabia, like the Gulf of Aden, the Red Sea and the elevation of the Afro-Arabian rift-flanks to heights above $3600 \mathrm{~m}[1,101,102]$.

The tempo and mode of the deep splits in Stenodactylus bear a striking resemblance to the basal splits that occurred in the African-Eurasian snake genus Echis [13,103], which suggests a common biogeographical pattern for both groups. The distribution of the members of Arabian clade B (S. doriae, S. leptocosymbotes, S. slevini, S. grandiceps, S. affinis) and the mainly African clade C (S. petrii, S. stenurus, S. yemenensis, S. mauritanicus, S. sthenodactylus) (Figures 1 and 2) extend primarily on the opposite sides of the Red Sea, mimicking the situation of the sister taxa E. coloratus (mainly Arabian) and E. pyramidum (mainly African). The split between these two Stenodactylus groups dates back to $21.8 \mathrm{Ma}$ ago (95\% HPD: 15.4-29.1) (Figure 2), which roughly coincides with the split between E. coloratus and E. pyramidum calculated at approximately 19.4 Ma ago. The dates of these phylogenetic events follow a well-studied phase of volcanism and strong rifting initiated at approximately $24 \mathrm{Ma}$ ago, that appeared in an almost synchronous way throughout the entire Red Sea [1]. Therefore, it is possible that the formation of the Red Sea acted as a vicariant event separating the aforementioned clades of Stenodactylus, as also suggested by Pook et al. (2009) [13] for the genus Echis. The agamid lizards of the genus Uromastyx [25] is yet another group that could have been affected by such an event, although in this case the split between the Arabian and African clades seems to have happened later, at 11-15 Ma ago. Amer and Kumazawa (2005) [25] attributed this split to a dispersal event from Arabia into North Africa, coinciding with climatic changes towards aridity in this latter area, rather than to vicariance. However, since earlier dates had also been calculated for the split between African and Arabian Uromastyx that coincide with the inferred dates for Stenodactylus and Echis (18 Ma ago; [104]), a reassessment of the calibration dates of Uromastyx using relaxed clock methods like the ones applied by Pook et al. (2009) [13] and in the present study seems necessary (work in progress).

The split between the Arabian S. yemenensis and the ancestor of the African S. mauritanicus and S. sthenodactylus on either sides of the Red Sea also parallels the splits between Arabian and African sister clades of the E. pyramidum complex [13] and Uromastyx ocellata and
$U$. ornata [25]. Although the divergence time estimate for the Stenodactylus members (15.4 Ma ago (95\% HPD: 10.5-20.8), Figure 2) predates the ones of the other two groups by almost $7 \mathrm{Ma}$, the split between African and Arabian lineages might be explained by the complex geology of the Red Sea. Several recurrent episodes during the Miocene caused the desiccation and refilling of this tectonically active rifting area $[1,105]$ and provoked the severing of the land bridges that had existed after the initial formation of the Red Sea in the early Miocene. So, the separation between $S$. yemenensis and the ancestor of S. mauritanicus and $S$. sthenodactylus was probably also the result of vicariance, similarly to Echis and Uromastyx. After this event, S. yemenensis would have remained isolated at the coastal side of the southern Arabian highlands (Figures 1 and 2).

In Arabia, an example of a similar biogeographical pattern caused by a different biogeographical process is the case of the ecologically similar sister species of clade A, $S$. pulcher and S. arabicus (including S. cf. arabicus), which, according to the results (Figure 2) and the geological data available, are hypothesized to result from vicariance caused by the uplift of the Yemen Mountains approximately $18 \mathrm{Ma}$ ago $[1,101,102]$. The splits within clade $\mathrm{B}$, however, seem more difficult to interpret, as little information is available on the geological and climatic history of the interior of Arabia. A general pattern could be proposed with a first North-South split between the ancestors of S. doriae, S. leptocosymbotes and S. slevini, S. grandiceps, S. affinis, respectively, followed by the posterior range expansion of some of these species. Interestingly, in Arabia, even though evidence exists for an increase in aridification [106], it has been hypothesized that at the same time an important river system, as evidenced by the fluvial sediments, could characterize the interior of the peninsula [93,107]. Such dynamic scenery could be responsible for the rapid diversification within clade B, having caused fragmentation of the distribution range of the ancestor(s) and the different lineages to split allopatrically.

The onset of diversification in clade B coincides in time with the split between the African S. mauritanicus and S. sthenodactylus in sub-clade C3 (Figure 2). These speciation events match very closely the estimates of the formation, in the late Miocene, of a major east-Antarctic ice sheet with its associated polar cooling, which triggered the aridification of mid-latitude continental regions and a shift in North Africa from forest to dry open woodlands and savannahs $[4,20,108]$. The two North African forms, S. mauritanicus and S. sthenodactylus, seem to have diverged in ecological niche, with one form adapted to mesic environments and the other occupying much dryer areas, respectively. It has been proposed that the gradual increase in aridity that took place in northern Africa during the late Miocene accelerated the diversification 
process in reptile faunas [21]. The estimated divergence times of the North African Stenodactylus seem to corroborate a common emerging pattern among European biota, according to which the speciation events in many reptile and amphibian groups do not coincide with the accentuated environmental instability during the Pleistocene, but rather date back into the Miocene and proceeding through the Quaternary, when many species and populations originated $[109,110]$.

It has been suggested that $18 \mathrm{Ma}$ ago, Africa connected with Eurasia through the closure of the Eastern Mediterranean seaway (the Gomphotherium land bridge) [15]. This land bridge later became disconnected temporarily but it has been continuously present since approximately $15 \mathrm{Ma}$ ago. It is interesting to notice that, despite the existence of a continuous passage between Arabia and Eurasia, our phylogeny suggests that colonization of Eurasia by members of the genus Stenodactylus occurred much later and was very restricted geographically. In fact, only two Stenodactylus species extend their ranges into Eurasia (S. affinis and $S$. doriae). From these two, only samples of $S$. affinis from Eurasia (Iran) were available, while for the other species a specimen from neighboring Kuwait was included. In both species, however, the low intraspecific genetic variability suggests that the colonization of Eurasia was a very recent event (Figure 2 and Additional file 3: Table S2b). One possible explanation of this biogeographical pattern may be the existence of ecologically and morphologically very similar forms in Iran like Crossobamon (formerly a member of Stenodactylus [39]) and Agamura, which may compete with Stenodactylus and therefore may have not allowed it to expand further outside the narrow coastal strip in southwestern Iran (Arnold, 1980). This situation is completely different than the one in North Africa, where no ecological analogs to Stenodactylus seem to exist and therefore several of its species are found across an area of more than 10 million $\mathrm{Km}^{2}$ [31,33,98,111,112].

\section{Conclusions}

The analyses presented in this study, based on a multilocus dataset that derives from a complete sampling of the 12 species of the genus Stenodactylus, reveal the existence of three clades with deep divergences within Stenodactylus and high intraspecific variability in some species, while the estimation of divergence times allows for biogeographical interpretations. The geckos Stenodactylus originated in Arabia $30 \mathrm{Ma}$ ago. In clade A, the split between the two species is hypothesized to have resulted from vicariance caused by the uplift of the Yemen Mountains approximately $18 \mathrm{Ma}$ ago. Stenodactylus $c f$. arabicus from the Sharqiya Sands constitutes a genetically and morphologically distinct lineage. In clade $\mathrm{B}$, rapid diversification seems to relate to climatic and geological instability in the late Miocene, but this hinders the reconstruction of robust phylogenetic relationships between some species. The Sharqiya Sands host yet another divergent lineage, that of the species $S$. doriae. In clade $C$, the split between S. yemenensis and sub-clade C3 is hypothesized to relate to the recurrent episodes of the desiccation and refilling of the Red Sea, during the Miocene. An interesting distribution pattern is revealed for the sister species $S$. sthenodactylus and S. mauritanicus, differing greatly from what was previously thought. Several speciation events in Stenodactylus are estimated to date back to the late Miocene, indicating that this was an important period for reptile diversification in this area. The split between clades $\mathrm{B}$ and $\mathrm{C}$ is attributed to the opening of the Red Sea in the Upper Miocene, acting as a vicariant agent. On the other hand, the formation of the connection between Africa and Eurasia seems to have had little effect on Stenodactylus, probably because of the existence of ecological analogs. On a taxonomic level, further studies are expected to resolve the systematics of the S. petrii - S. stenurus complex. Validity of the specific status of $S$. mauritanicus is confirmed with mitochondrial and nuclear data. Overall, this work unveils the evolutionary history of Stenodactylus geckos and highlights their use as a model in the study of the faunal interchanges between North Africa and Arabia and the evolutionary processes in these arid areas.

\section{Additional files}

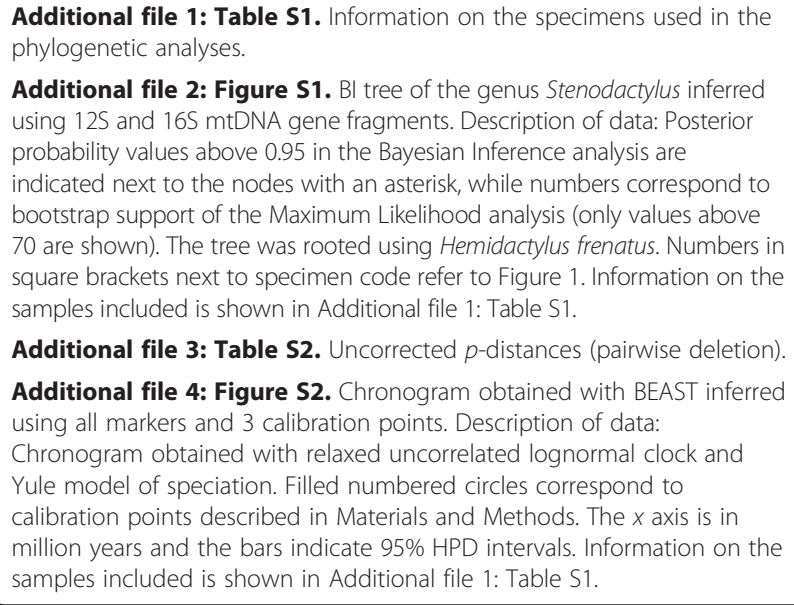

Additional file 2: Figure S1. BI tree of the genus Stenodactylus inferred using 125 and 165 mtDNA gene fragments. Description of data: Posterior probability values above 0.95 in the Bayesian Inference analysis are indicated next to the nodes with an asterisk, while numbers correspond to bootstrap support of the Maximum Likelihood analysis (only values above 70 are shown). The tree was rooted using Hemidactylus frenatus. Numbers in square brackets next to specimen code refer to Figure 1. Information on the samples included is shown in Additional file 1: Table S1.

Additional file 3: Table S2. Uncorrected $p$-distances (pairwise deletion).

Additional file 4: Figure S2. Chronogram obtained with BEAST inferred using all markers and 3 calibration points. Description of data:

Chronogram obtained with relaxed uncorrelated lognormal clock and Yule model of speciation. Filled numbered circles correspond to calibration points described in Materials and Methods. The $x$ axis is in million years and the bars indicate 95\% HPD intervals. Information on the samples included is shown in Additional file 1: Table S1.

\section{Abbreviations}

rRNA: ribosomal ribonucleic acid; c-mos: oocyte maturation factor Mos; RAG-2: Recombination activating gene 2; PCR: Polymerase chain reaction; ML: Maximum likelihood; BI: Bayesian Inference; AU: Approximately unbiased; SH: Shimodaira-Hasegawa; BF: Bayes factor; Ma: Megaannum; HPD: Highest posterior density.

\section{Competing interests}

The authors declare that they have no competing interests. 


\section{Authors' contributions}

SC and ENA conceived the study. SC coordinated the study. All authors collected samples in the field and/or provided tissue samples. SC and MM assembled the data. MM obtained the sequences, carried out the analyses and drafted the manuscript. PAC contributed to improving the manuscript. MM and SC wrote the final manuscript. All authors read and approved the final manuscript.

\section{Acknowledgements}

The authors are grateful to people who donated samples for this study or helped in the field: F Ahmadzadeh, F Amat, A Bouskila, A Cluchier, O Chaline, M Charpentier, D Donaire, D Escoriza, T Gamble, J Harris, Y Hingrat, $H$ in den Bosch. D Modry, J Padial, O Peyre, JM Pleguezuelos, C Rato, J Renoult, B Shacham, J Smid, J Viglione. We are especially grateful to Jiri Moravec and Lukas Kratochvil for providing the S. stenurus tissue sample and the photograph of the species. We would also like to thank Elena Gómez-Diaz for providing helpful comments and Enric Planas for fruitful discussion and help with the figures. We are indebted to Ali Alkiyumii and the other members of the Ministry of Environment and Climate Affairs of the Sultanate of Oman for their help and support and for issuing collecting permits (Refs: 08/2005; 16/2008; 38/2010; 12/2011). This work was supported by grants CGL2009-11663/BOS from the Ministerio de Economía y Competitividad, Spain, Fondos FEDER - EU, and 2012RU0055 from the Consejo de Investigaciones Cientificas (CSIC) and the Russian Foundation for Basic Research (RFBR). SC and MM are members of the Grup de Recerca Emergent of the Generalitat de Catalunya: 2009SGR1462; MM is supported by a FPU predoctoral grant from the Ministerio de Educación, Cultura y Deporte, Spain (AP2008-01844). Some phylogenetic analyses were run in the cluster facility of the IBE funded by the Spanish National Bioinformatics Institute (http:// www.inab.org) and in the CIPRES Science Gateway web portal. We acknowledge support of the publication fee by the CSIC Open Access Publication Support Initiative through its Unit of Information Resources for Research (URICI). We thank two anonymous reviewers for helpful comments on an earlier version of the manuscript.

\section{Author details}

'Institute of Evolutionary Biology (CSIC-UPF), Passeig Marítim de la Barceloneta 37-49, Barcelona 08003, Spain. ${ }^{2}$ The Natural History Museum, Cromwell Road, London SW7 5BD, UK. ${ }^{3}$ CNRS-UMR 5175 Centre d'Ecologie Fontionnelle et Evolutive, 1919 Route de Mende, 34293, Montpellier cedex 5, France. ${ }^{4}$ EPHE-UMR, Centre d'Ecologie Fontionnelle et Evolutive, 1919 Route de Mende, 34293, Montpellier cedex 5, France. ${ }^{5} \mathrm{CIBIO} / \mathrm{InBIO}$, Centro de Investigação em Biodiversidade e Recursos Genéticos da Universidade do Porto, Instituto de Ciências Agrárias de Vairão, R. Padre Armando Quintas 4485-661, Vairão, Portugal. ${ }^{6}$ Natural History Museum of Crete, University of Crete, Knosou Av, P.O. Box 220871409, Heraklion, Greece. ${ }^{7}$ Nature Conservation Sector, Egyptian Environmental Affairs Agency, 3 Abdalla EI Katib, Apt. 3, Cairo, Dokki, Egypt. ${ }^{8}$ Museo Civico de Storia Naturale, via San Francesco di Sales 188, Carmagnola I-10022, Italy. ${ }^{9}$ Sultan Qaboos University, Department of Biology, College of Science, P.O. Box 36Al-Khod, Muscat, Sultanate of Oman.

Received: 20 September 2012 Accepted: 3 December 2012 Published: 31 December 2012

\section{References}

1. Bosworth W, Huchon P, McClay K: The Red Sea and Gulf of Aden Basins. J Afr Earth Sci 2005, 43:334-378.

2. Carranza S, Arnold EN, Geniez P, Roca J, Mateo J: Radiation, multiple dispersal and parallelism in the skinks, Chalcides and Sphenops (Squamata: Scincidae), with comments on Scincus and Scincopus and the age of the Sahara desert. Mol Phylogenet Evol 2008, 46:1071-1094.

3. Dean WRJ: Nomadic Desert Birds. Berlin, Heidelberg, New York: Springer Verlag; 2004

4. Flower BP, Kennett JP: The middle Miocene climatic transition: East Antarctic ice sheet development, deep ocean circulation and global carbon cycling. Palaeogeogr Palaeoclimatol Palaeoecol 1994, 108:537-555.

5. Griffin DL: Aridity and humidity: two aspects of the late Miocene climate of North Africa and the Mediterranean. Palaeogeogr Palaeoclimatol Palaeoecol 2002, 182:65-91
6. Guiraud R, Bosworth W, Thierry J, Delplanque A: Phanerozoic geological evolution of Northern and Central Africa: an overview. J Afr Earth Sci 2005, 43:83-143

7. Lourenço W, Duhem B: Saharo-Sindian buthid scorpions; description of two new genera and species from Occidental Sahara and Afghanistan. Zookeys 2009, 14:37-54.

8. Quezel P: Analysis of the flora of Mediterranean and Saharan Africa. Ann Mo Bot Gard 1978, 65:479-534.

9. Yom-Tov Y: Character displacement in the Psammophile Gerbillidae of Israel. Oikos 1991, 60:173-179.

10. Haq BU, Hardenbol J, Vail PR: Chronology of fluctuating sea levels since the Triassic. Science 1987, 235:1156-1167.

11. Fernandes CA, Rohling EJ, Siddall M: Absence of post-Miocene Red Sea land bridges: biogeographic implications. J Biogeogr 2006, 33:961-966.

12. Harzhauser M, Kroh A, Mandic O, Piller WE, Göhlich U, Reuter M, Berning B: Biogeographic responses to geodynamics: a key study all around the Oligo-Miocene Tethyan Seaway. Zoologischer Anzeiger-A Journal of Comparative Zoology 2007, 246:241-256.

13. Pook CE, Joger U, Stümpel N, Wüster W: When continents collide: phylogeny, historical biogeography and systematics of the medically important viper genus Echis (Squamata: Serpentes: Viperidae). Mol Phylogenet Evol 2009, 53:792-807.

14. Zhou L, Su YCF, Thomas DC, Saunders RMK: 'Out-of-Africa' dispersal of tropical floras during the Miocene climatic optimum: evidence from Uvaria (Annonaceae). J Biogeogr 2012, 39:322-335.

15. Rögl F: Paleogeographic Considerations For Mediterranean And Paratethys Seaways (Oligocene And Miocene). Wien: Annalen des Naturhistorischen Museums in; 1998. 99A: 279-331.

16. Kroepelin S: Revisiting the age of the Sahara desert. Science 2006, 312:1138-1139.

17. Schuster M: Revisiting the age of the Sahara Desert. Science 2006, 312:1138-1139.

18. Schuster M, Duringer $P$, Ghienne J-F, Vignaud $P$, Mackaye $H T$, Likius A, Brunet M: The age of the Sahara desert. Science 2006, 311:821.

19. Swezey CS: Revisiting the age of the Sahara desert. Science 2006, 312:1138-1139.

20. Douady CJ, Catzeflis F, Raman J, Springer MS, Stanhope MJ: The Sahara as a vicariant agent, and the role of Miocene climatic events, in the diversification of the mammalian order Macroscelidea (elephant shrews). Proc Natl Acad Sci 2003, 100:8325-8330.

21. Fu J: Toward the phylogeny of the family Lacertidae-Why 4708 base pairs of mtDNA sequences cannot draw the picture. Biol J Linn Soc 2000, 71:203-217.

22. Guillaumet A, Crochet PA, Pons JM: Climate-driven diversification in two widespread Galerida larks. BMC Evol Biol 2008, 8:32.

23. Camargo A, Sinervo B, Sites JW Jr: Lizards as model organisms for linking phylogeographic and speciation studies. Mol Ecol 2010, 19:3250-3270.

24. Kapli P, Lymberakis P, Poulakakis N, Mantziou G, Parmakelis A, Mylonas M: Molecular phylogeny of three Mesalina (Reptilia: Lacertidae) species (M. guttulata, M. brevirostris and M. bahaeldini) from North Africa and the Middle East: another case of paraphyly? Mol Phylogenet Evol 2008, 49:102-110.

25. Amer SAM, Kumazawa Y: Mitochondrial DNA sequences of the AfroArabian spiny-tailed lizards (genus Uromastyx; family Agamidae): phylogenetic analyses and evolution of gene arrangements. Biol I Linn Soc 2005, 85:247-260.

26. Carranza S, Arnold EN, Mateo JA, Geniez P: Relationships and evolution of the North African geckos, Geckonia and Tarentola (Reptilia: Gekkonidae), based on mitochondrial and nuclear DNA sequences. Mol Phylogenet Evol 2002, 23:244-256.

27. Carranza S, Arnold EN, Pleguezuelos JM: Phylogeny, biogeography, and evolution of two Mediterranean snakes, Malpolon monspessulanus and Hemorrhois hippocrepis (Squamata, Colubridae), using mtDNA sequences. Mol Phylogenet Evol 2006, 40:532-546.

28. Fonseca MM, Brito JC, Rebelo H, Kalboussi M, Larbes S, Carretero MA, Harris DJ: Genetic variation among spiny-footed lizards in the Acanthodactylus pardalis group from North Africa. African Zoology 2008, 43:8-15.

29. Gonçalves DV, Brito JC, Crochet PA, Geniez P, Padial JM, Harris DJ: Phylogeny of North African Agama lizards (Reptilia: Agamidae) and the role of the Sahara desert in vertebrate speciation. Mol Phylogenet Evol 2012, 64:582-591. 
30. Fitzinger LJ: Neue Classification Der Reptilien Nach Ihren Natürlichen Verwandtschaften: Nebst Einer Verwandtschafts-Tafel Und Einem Verzeichnisse Der Reptilien-Sammlung Des KK Zoologischen Museum's Zu Wien. Wien: JG Heubner; 1826.

31. Arnold EN: Reptiles of Saudi Arabia: a review of the lizard genus Stenodactylus (Reptilia: Gekkonidae). Fauna of Saudia Arabia 1980, 2:368-404.

32. Arnold EN: Little-known geckoes (Reptilia: Gekkonidae) from Arabia with descriptions of two new species from the Sultanate of Oman. The Scientific Results of the Oman Flora and Fauna Survey 1975, 1977:81-110.

33. Sindaco R, Jeremcenko VK: The Reptiles Of The Western Palearctic. Latina (Italy): Edizioni Belvedere; 2008.

34. Arnold EN: Ecology of lowland lizards in the eastern United Arab Emirates. J Zool 1984, 204:329-354.

35. Blanford WT: Descriptions of new reptilia and amphibia from Persia and Baluchistan. The Annals and Magazine of Natural History, London 1874, 4:31-35.

36. Anderson J: A Contribution To The Herpetology Of Arabia: With A Preliminary List Of The Reptiles And Batrachians Of Egypt. London: RH Porter; 1896.

37. Haas G: Some amphibians and reptiles from Arabia. Proc Calif Acad Sci 1957, 29:47-86.

38. Bauer AM, Russell AP: Pedal specialisations in dune-dwelling geckos. J Arid Environ 1991, 20:43-62.

39. Kluge AG: Higher taxonomic categories of gekkonid lizards and their evolution. Bull Am Mus Nat Hist 1967, 135:1-60.

40. Fujita MK, Papenfuss TJ: Molecular systematics of Stenodactylus (Gekkonidae), an Afro-Arabian gecko species complex. Mol Phylogenet Evol 2011, 58:71-75

41. Arnold EN: Relationships, evolution and biogeography of Semaphore geckos, Pristurus (Squamata, Sphaerodactylidae) based on morphology. Zootaxa 2009, 2060:1-21.

42. Arnold EN, Vasconcelos R, Harris DJ, Mateo JA, Carranza S: Systematics, biogeography and evolution of the endemic Hemidactylus geckos (Reptilia, Squamata, Gekkonidae) of the Cape Verde Islands: based on morphology and mitochondrial and nuclear DNA sequences. Zoologica Scripta 2008, 37:619-636.

43. Carranza S, Arnold EN: Systematics, biogeography, and evolution of Hemidactylus geckos (Reptilia: Gekkonidae) elucidated using mitochondrial DNA sequences. Mol Phylogenet Evol 2006, 38:531-545.

44. Carranza S, Arnold EN: A review of the geckos of the genus Hemidactylus (Squamata: Gekkonidae) from Oman based on morphology, mitochondrial and nuclear data, with descriptions of eight new species. Zootaxa 2012, 3378:1-95.

45. Carranza S, Arnold EN, Mateo JA, López-Jurado LF: Long-distance colonization and radiation in gekkonid lizards, Tarentola (Reptilia: Gekkonidae), revealed by mitochondrial DNA sequences. Proc $R$ Soc London, Ser B 2000, 267:637.

46. Gamble T, Bauer AM, Colli GR, Greenbaum E, Jackman TR, Vitt L, Simons AM: Coming to America: multiple origins of New World geckos. J Evol Biol 2011, 24:231-244.

47. Feng J, Han D, Bauer AM, Zhou K: Interrelationships among Gekkonid Geckos inferred from mitochondrial and nuclear gene sequences. Zoolog Sci 2007, 24:656-665.

48. Gamble T, Bauer AM, Greenbaum E, Jackman TR: Out of the blue: a novel, trans-Atlantic clade of geckos (Gekkota, Squamata). Zoologica Scripta 2008, 37:355-366

49. Han D, Zhou K, Bauer AM: Phylogenetic relationships among gekkotan lizards inferred from C-mos nuclear DNA sequences and a new classification of the Gekkota. Biol J Linn Soc 2004, 83:353-368.

50. Drummond AJ, Ashton B, Buxton S, Cheung M, Cooper A, Heled J, Kearse M, Moir R, Stones-Havas S, Sturrock S: Geneious v5. 1. 2010. Available from www.geneious.com

51. Katoh K, Toh H: Recent developments in the MAFFT multiple sequence alignment program. Brief Bioinform 2008, 9:286-298.

52. Tamura K, Peterson D, Peterson N, Stecher G, Nei M, Kumar S: MEGA5: molecular evolutionary genetics analysis using maximum likelihood, evolutionary distance, and maximum parsimony methods. Mol Biol Evol 2011, 28:2731-2739.

53. Akaike $\mathrm{H}$ : Information theory and an extension of the maximum likelihood principle. In Second International Symposium on Information Theory. Edited by Petrov BN, Csaki F. Budapest (Hungary): Akademiai Kiado; 1973:267-281.
54. Posada D: jModelTest: phylogenetic model averaging. Mol Biol Evol 2008, 25:1253

55. Huelsenbeck JP, Ronquist F: MRBAYES: Bayesian inference of phylogenetic trees. Bioinformatics 2001, 17:754-755.

56. Ronquist F, Huelsenbeck JP: MrBayes 3: Bayesian phylogenetic inference under mixed models. Bioinformatics 2003, 19:1572-1574.

57. Stamatakis A: RAxML-VI-HPC: maximum likelihood-based phylogenetic analyses with thousands of taxa and mixed models. Bioinformatics 2006 22:2688.

58. Felsenstein J: Confidence limits on phylogenies: an approach using the bootstrap. Evolution 1985, 39:783-791.

59. Stephens M, Scheet P: Accounting for decay of linkage disequilibrium in haplotype inference and missing-data imputation. Am J Hum Genet 2005, 76:449-462.

60. Stephens M, Smith NJ, Donnelly P: A new statistical method for haplotype reconstruction from population data. Am J Hum Genet 2001, 68:978-989.

61. Flot JF: Seqphase: a web tool for interconverting phase input/output files and fasta sequence alignments. Mol Ecol Resour 2010, 10:162-166.

62. Clement M, Posada D, Crandall KA: TCS: a computer program to estimate gene genealogies. Mol Ecol 2000, 9:1657-1659.

63. Shimodaira $\mathrm{H}$ : An approximately unbiased test of phylogenetic tree selection. Syst Biol 2002, 51:492

64. Shimodaira H, Hasegawa M: Multiple comparisons of log-likelihoods with applications to phylogenetic inference. Mol Biol Evol 1999, 16:1114-1116.

65. Shimodaira $\mathrm{H}$, Hasegawa M: CONSEL: for assessing the confidence of phylogenetic tree selection. Bioinformatics 2001, 17:1246.

66. Suchard MA, Weiss RE, Sinsheimer JS: Models for estimating bayes factors with applications to phylogeny and tests of monophyly. Biometrics 2005, 61:665-673.

67. Drummond AJ, Rambaut A: BEAST: Bayesian evolutionary analysis by sampling trees. BMC Evol Biol 2007, 7:214.

68. Rambaut A, Drummond AJ: Tracer v1. 4, 2007 [http://beast.bio.ed.ac.uk Tracer].

69. Ho SYW, Phillips MJ, Cooper A, Drummond AJ: Time dependency of molecular rate estimates and systematic overestimation of recent divergence times. Mol Biol Evol 2005, 22:1561-1568.

70. Gamble T, Bauer AM, Greenbaum E, Jackman TR: Evidence for Gondwanan vicariance in an ancient clade of gecko lizards. J Biogeogr 2008, 35:88-104.

71. Vasconcelos R, Carranza S, Harris DJ: Insight into an island radiation: the Tarentola geckos of the Cape Verde archipelago. J Biogeogr 2010, 37:1047-1060.

72. Agustí J, Cabrera L, Garcés M, Krijgsman W, Oms O, Parés JM: A calibrated mammal scale for the Neogene of Western Europe. State of the art. EarthScience Reviews 2001, 52:247-260.

73. Müller J: A new fossil species of Euleptes from the early Miocene of Montaigu, France (Reptilia, Gekkonidae). Amphibia-Reptilia 2001, 22:341-348.

74. Abdrakhmatov KY, Aldazhanov SA, Hager BH, Hamburger MW, Herring TA, Kalabaev KB, Makarov VI, Molnar P, Panasyuk SV, Prilepin MT, et al: Relatively recent construction of the Tien Shan inferred from GPS measurements of present-day crustal deformation rates. Nature 1996, 384:450-453.

75. Macey JR, Wang Y, Ananjeva NB, Larson A, Papenfuss TJ: Vicariant patterns of fragmentation among Gekkonid lizards of the Genus Teratoscincus produced by the Indian collision: a molecular phylogenetic perspective and an area cladogram for Central Asia. Mol Phylogenet Evol 1999, 12:320-332.

76. Tapponnier P, Mattauer M, Proust F, Cassaigneau C: Mesozoic ophiolites, sutures, and large-scale tectonic movements in Afghanistan. Earth Planet Sci Lett 1981, 52:355-371.

77. Guillou H, Carracedo JC, Torrado FP, Badiola ER: K-Ar ages and magnetic stratigraphy of a hotspot-induced, fast grown oceanic island: El Hierro, Canary Islands. J Volcanol Geotherm Res 1996, 73:141-155.

78. Arnold EN, Arribas O, Carranza S: Systematics of the Palaearctic and Oriental lizard tribe Lacertini (Squamata: Lacertidae: Lacertinae), with descriptions of eight new genera. Zootaxa 2007, 1430:1-86.

79. Brown RP, Yang Z: Bayesian dating of shallow phylogenies with a relaxed clock. Syst Biol 2010, 59:119.

80. Cox SC, Carranza S, Brown RP: Divergence times and colonization of the Canary Islands by Gallotia lizards. Mol Phylogenet Evol 2010, 56:747-757.

81. Maddison DR, Maddison WP: MacClade 4.0. Sunderland, Massachusetts: Sinauer; 2000 
82. Maddison WP, Maddison DR: Mesquite: A Modular System For Evolutionary Analysis. Version 2.73. http://mesquiteproject.org.

83. Leviton $A E$, Anderson SC: Survey of the reptiles of the Sheikhdom of Abu Dhabi, Arabian Peninsula. Part II. Systematic account of the collection of reptiles made in the Sheikhdom of Abu Dhabi by John Gasperetti. Proc Calif Acad Sci 1967, 35:157-192.

84. Haas G: Two collections of Reptiles from Iraq, with descriptions of two new forms. Copeia 1952, 1952:20-22.

85. Murray JA: Additions to the present knowledge of the vertebrate Zoology of Persia. The Annals and Magazine of Natural History 1884, 14:97-106.

86. Werner F: Allerlei aus dem Kriechtierleben im Käfig. II. Zoologischer Garten, Frankfurt am Main 1899, 40:12-24.

87. Guichenot AA: Histoire Naturelle Des Reptiles Et Des Poissons. Paris: Imprimerie nationale; 1850

88. Gardner RAM: Aeolianites and marine deposits of the Wahiba Sands: character and palaeoenvironments. The Journal of Oman Studies 1988, 3:1985-1987.

89. Preusser F, Radies D, Driehorst F, Matter A: Late Quaternary history of the coastal Wahiba Sands, Sultanate of Oman. J Quat Sci 2005, 20:395-405.

90. Preusser F, Radies D, Matter A: A 160,000-year record of Dune development and atmospheric circulation in Southern Arabia. Science 2002, 296:2018-2020

91. Gallagher MD, Arnold EN: Reptiles and amphibians from the Wahiba Sands, Oman. J Oman Stud, Spec Rep 1988, 3:405-413.

92. Blanford WT: Descriptions of new lizards from Persia and Baluchistan. Ann Mag Nat Hist 1874, 13:453-455.

93. Garzanti E, Andò S, Vezzoli G, Dell'era D: From rifted margins to foreland basins: investigating provenance and sediment dispersal across desert Arabia (Oman, U.A.E.). J Sediment Res 2003, 73:572-588.

94. Knowles LL, Carstens BC: Delimiting species without monophyletic gene trees. Syst Biol 2007, 56:887-895.

95. Werner F: Reptilien, Batrachier und Fische von Tripolis und Barka. Zoologische Jahrbucher Abteilung fur Systematik, Geographie und Biologie der Tiere 1909, 27:595-646.

96. Kratochvil L, Frynta D, Moravec J: Third Stenodactylus in Africa: return of the forgotten form Stenodactylus stenurus. Israel Journal of Zoology 2001, 47:99-110.

97. Barbour T: Notes on some reptiles from Sinai and Syria. Proceedings of the New England Zoological Club 1914, 5:73-92.

98. Baha El Din S: A Guide to the Reptiles and Amphibians of Egypt. Cairo and New York: The American University in Cairo Press, xvi; 2006.

99. Loveridge A: Revision of the African lizards of the family Gekkonidae. Bulletin of the Mus Comp Zool, Harvard 1947, 98:1-469.

100. Loveridge A: Checklist of the reptiles and amphibians of East Africa. Bulletin of The Museum of Comparative Zoology 1957, 117:151-362.

101. Menzies MA, Baker J, Bosence D, Dart C, Davison I, Hurford A, Al'Kadasi M, McClay K, Nichols G, Al'Subbary A, Yelland A: The timing of magmatism, uplift and crustal extension: preliminary observations from Yemen. Geological Society, London, Special Publications 1992, 68:293-304.

102. Autin J, Leroy S, Beslier MO, DíAcremont E, Razin P, Ribodetti A, Bellahsen N, Robin C, Al Toubi K: Continental break up history of a deep magma poor margin based on seismic reflection data (northeastern Gulf of Aden margin, offshore Oman). Geophys J Int 2010, 180:501-519.

103. Arnold EN, Robinson MD, Carranza S: A preliminary analysis of phylogenetic relationships and biogeography of the dangerously venomous Carpet Vipers, Echis (Squamata, Serpentes, Viperidae) based on mitochondrial DNA sequences. Amphibia-Reptilia 2009, 30:273-282.

104. Joger U: Phylogenetic analysis of Uromastyx lizards, based on albumin immunological distances. In Studies in Herpetology. Edited by Rocek Z. Bonn, Germany: Societas Europaea Herpetologica; 1986:187-192.

105. Girdler RW: The Afro-Arabian rift system - an overview. Tectonophysics 1991, 197:139-153.

106. Huang Y, Clemens SC, Liu W, Wang Y, Prell WL: Large-scale hydrological change drove the late Miocene C4 plant expansion in the Himalayan foreland and Arabian Peninsula. Geology 2007, 35:531-534.

107. Friend PF: Rivers of the Lower Baynunah Formation, Emirate of Abu Dhabi, United Arab Emirates. In Fossil Vertebrates Of Arabia, With Emphasis On The Late Miocene Faunas, Geology, And Palaeoenvironments Of The Emirate Of Abu Dhabi, United Arab Emirates. New Haven, Connecticut: Yale University Press; 1999:38-49.
108. Zachos J, Pagani M, Sloan L, Thomas E, Billups K: Trends, rhythms, and aberrations in global climate 65 Ma to Present. Science 2001, 292:686-693.

109. Paulo OS, Dias C, Bruford MW, Jordan WC, Nichols RA: The persistence of Pliocene populations through the Pleistocene climatic cycles: evidence from the phylogeography of an Iberian lizard. Proc $R$ Soc London, Ser $B$ 2001, 268:1625-1630.

110. Tzedakis PC, Lawson IT, Frogley MR, Hewitt GM, Preece RC: Buffered tree population changes in a quaternary refugium: evolutionary implications. Science 2002, 297:2044-2047.

111. Bons J, Geniez P: Amphibians And Reptiles Of Morocco. Barcelona: Asociación herpetológica Española; 1996.

112. Schleich HH, Kästle W, Kabisch K: Amphibians And Reptiles Of North Africa: Biology, Systematics, Field Guide. Königstein, Germany: Koeltz Scientific Books; 1996.

doi:10.1186/1471-2148-12-258

Cite this article as: Metallinou et al.: Conquering the Sahara and Arabian deserts: systematics and biogeography of Stenodactylus geckos (Reptilia: Gekkonidae). BMC Evolutionary Biology 2012 12:258.

\section{Submit your next manuscript to BioMed Central and take full advantage of:}

- Convenient online submission

- Thorough peer review

- No space constraints or color figure charges

- Immediate publication on acceptance

- Inclusion in PubMed, CAS, Scopus and Google Scholar

- Research which is freely available for redistribution 